\title{
Untreated Initial Psychosis: Relation to Cognitive Deficits and Brain Morphology in First-Episode Schizophrenia
}

\author{
Beng-Choon Ho, M.R.C.Psych. \\ Daniel Alicata, M.D. \\ Julianna Ward, Ph.D. \\ David J. Moser, Ph.D. \\ Daniel S. 0’Leary, Ph.D.
}

Stephan Arndt, Ph.D.

Nancy C. Andreasen, M.D., Ph.D.

\begin{abstract}
Objective: Studies of patients experiencing their first episode of psychosis have demonstrated that they typically remain undiagnosed and untreated for 1-2 years. It has been postulated that prolonged untreated psychosis may have serious effects: poor response to neuroleptic medications, poor clinical outcomes, and direct neurotoxicity. This study investigated the relationships between duration of untreated initial psychosis and neurocognitive functioning and high-resolution imaging brain measurements.
\end{abstract}

Method: A total of 156 subjects with DSM-
IV schizophrenia, schizophreniform dis-
order, or schizoaffective disorder were
evaluated during their first episode of
psychosis. Measurements included nine
domains of neurocognitive functioning,
volumetric measures of total brain tissue,
gray and white matter, and CSF, and mea-
sures of brain surface anatomy.

Results: The mean duration of untreated initial psychosis was 74.3 weeks. Correla- tions between neurocognitive functioning, brain volumetric measurements, and surface anatomy measurements with duration of untreated initial psychosis were weak; none reached statistical significance. When the group was divided on the basis of median duration of untreated initial psychosis, there were again no significant differences between the groups with long and short duration of untreated initial psychosis except on two measures (verbal memory and cortical sulcal depth).

Conclusions: The absence of strong correlations suggests that untreated initial psychosis has no direct toxic neural effects. These results suggest that large-scale initiatives designed to prevent neural injury through early intervention in the prepsychotic or early psychosis phase may be based on incorrect assumptions that neurotoxicity or cognitive deterioration may be avoided. Nevertheless, early treatment is justified because it reduces suffering.
A of first-episode psychosis is the lengthy delay between onset of first psychotic symptoms and the start of treatment (1). This duration of untreated initial psychosis usually averages between 1 and 2 years. The reasons for, and ramifications of, such lengthy delays have become a focus of attention both in research and in health care delivery (1-4). One concern regarding treatment delays is the potential for untreated psychosis to be toxic to the brain $(5,6)$. Epidemiological studies, mirror-image studies, and early antipsychotic treatment trials have been cited as supportive of this "toxic psychosis" hypothesis (5). However, studies that have specifically examined the relationship between duration of untreated initial psychosis and outcome have had more mixed findings (4) and call into question the plausibility of toxicity from untreated psychosis. Although there are presently still more publications in the literature reporting on the association between long duration of untreated initial psychosis and poor outcome (7-16), an increasing number of studies published during the past 3 years have failed to find this association (17-22).

The purported toxicity of untreated psychosis may be biologically or psychosocially mediated. It has been pos- tulated that $N$-methyl-D-aspartic acid receptor hypofunction may induce psychosis and produce glutamate excitotoxic damage in neurons at the same time (23). Alternatively, prolonged stress, including stress resulting from untreated psychosis, can activate the hypothalamicpituitary-adrenal axis, leading to greater glucocorticoid secretion, which then brings about neuronal injury (24). The neurotoxicity postulated to arise through these biological mechanisms would, in turn, lead to impaired functioning and worsen outcome in schizophrenia. Besides biological toxicity, prolonged duration of untreated initial psychosis may impair subsequent outcome through psychosocial factors, such as missed educational and employment opportunities, devastation of self-esteem, and reduction in the psychosocial support network.

The aim of this study was to test whether untreated psychosis may be biologically toxic. In a previous study, our group found that a longer duration of untreated initial psychosis did not significantly impair quality of life, symptom severity, or remission of positive symptoms 6 months after a first psychiatric hospitalization (18). In this current study, which has the largest group of first-episode subjects collected to date to our knowledge, we examined whether 
untreated psychosis has toxic effects on brain tissue and function using the tools of anatomic magnetic resonance imaging (MRI) and tests of cognition. We hypothesized that if psychosis is biologically toxic, exposure to longer periods of untreated psychosis would lead to poorer cognitive functioning and greater abnormalities in brain structure.

\section{Method}

\section{Subjects}

A total of 156 subjects (97 male and 59 female) were evaluated during their first episode of psychotic illness at the University of Iowa's Mental Health Clinical Research Center. Subjects were assessed by using the Comprehensive Assessment of Symptoms and History (25), within which the Scale for the Assessment of Negative Symptoms (26) and the Scale for the Assessment of Positive Symptoms (27) are integrated. In addition to interviews with the subjects, supplemental information was obtained from collateral sources, including family members and previous medical records, to complete the comprehensive intake evaluation. Written informed consent, approved by the University of Iowa's institutional review board, was obtained from each subject.

No subjects had received more than 3 months of cumulative lifetime antipsychotic treatment (duration of previous antipsychotic treatment: mean $=0.35$ months, $\mathrm{SD}=0.54$ ); $79.5 \%$ of the group was neuroleptic naive. The majority of the subjects had DSM-IV schizophrenia $(\mathrm{N}=114)$; the remaining subjects had either schizophreniform disorder $(\mathrm{N}=36)$ or schizoaffective disorder $(\mathrm{N}=6)$. Diagnoses were based on a semistructured interview (the Comprehensive Assessment of Symptoms and History). The mean age of illness onset was 22.7 years $(\mathrm{SD}=6.7)$, and the mean age at first hospitalization was 25.8 years $(\mathrm{SD}=8.4)$. Being in the midst of their first episode of psychosis, the subjects were moderately ill (negative symptom severity [sum of global ratings for alogia, anhedonia, avolition, and affective flattening]: mean=11.53, $\mathrm{SD}=3.56$; psychotic symptom severity [sum of global ratings for delusions and hallucinations]: mean $=6.45, \mathrm{SD}=2.41$; disorganized symptom severity [sum of global ratings for disorganized behavior, positive formal thought disorder, and inappropriate affect]: mean $=5.49, \mathrm{SD}=2.60$ ).

As previously described (18), duration of untreated initial psychosis was defined as the time period from the onset of the full positive syndrome to the initiation of antipsychotic treatment. "Full psychotic syndrome" was defined as the presence of any one of five positive symptoms (i.e., delusions, hallucinations, bizarre [disorganized] behaviors, positive formal thought disorder, and catatonic motor behavior) rated at a severity level of moderate or worse. The interrater reliability (intraclass $r$ ) for assessment of duration of untreated initial psychosis was 0.87 (25).

\section{Neurocognitive Assessment}

All study subjects were administered a comprehensive cognitive battery by psychometrists who had been trained in standardized assessment and scoring procedures. Testing generally took 4 hours to complete and, when necessary, occurred over several sessions.

In order to provide comprehensive yet efficient measurements of the subjects' cognitive functioning, 36 neuropsychological test variables were grouped into nine cognitive domains: verbal memory, nonverbal memory, working memory, language skills, visuospatial skills, initiation and speed, sustained and selective attention, problem solving, and motor skills (Appendix 1). By summarizing our neuropsychological battery into cognitive domains, we limited capitalizing on chance associations in subsequent statistical analyses. With Cronbach's alpha, these nine theoretical cognitive domains were tested for internal reliability (by J.W.) in schizophrenia patients as well as among healthy compar- ison subjects. Each cognitive domain had good internal consistency (Cronbach's alpha: median=0.785).

Before deriving domain scores for the 156 schizophrenia subjects in this study, the age-standardized raw test score for each of the 36 neuropsychological test variables was converted to a $\mathrm{z}$ score (mean $=0, \mathrm{SD}=1$ ) on the basis of norms established by use of 488 healthy comparison subjects. To provide a consistent and uniform basis for establishing the norms, these healthy comparison subjects were recruited from the same geographical area from which the schizophrenia subjects were ascertained. The same psychometrists who administered the neuropsychological battery to our patients also tested these healthy comparison subjects. Scores were reversed where necessary so that a larger negative score would indicate poor performance below the mean. With these $\mathrm{z}$ scores, each domain score is the summed average of its component neuropsychological test variables (Appendix 1).

\section{MRI and Brain Morphology Measures}

Images were obtained on a 1.5-T GE (Milwaukee) Signa MRI scanner. Three different MRI sequences were used for each subject. $\mathrm{T}_{1}$-weighted spoiled grass sequences were acquired with the following parameters: 124 1.5- $\mathrm{mm}$ coronal slices, $\mathrm{TE}=5 \mathrm{msec}, \mathrm{TR}=$ $24 \mathrm{msec}$, flip angle $=40^{\circ}$, number of excitations $=2$, field of view $=26$ $\mathrm{cm}$, matrix $=256 \times 192$, and echo train length $=8$. Proton density and $\mathrm{T}_{2}$-weighted images were acquired with the following parameters: 3-mm coronal slices, $\mathrm{TE}=36 \mathrm{msec}$ (for proton density) or 96 msec (for $\mathrm{T}_{2}$ ), $\mathrm{TR}=3000 \mathrm{msec}$, number of excitations=1, field of view $=26 \mathrm{~cm}$, matrix $=256 \times 192$, and echo train length $=8$. All scans were rated for overall quality and for movement artifacts by using a $0-4$ scale $(0=$ very poor, $4=$ excellent $)$. All scans in this study received quality ratings between good and excellent.

Image processing was performed by using the BRAINS (Brain Research: Analysis of Images, Networks, and Systems) software package (Iowa City, Mental Health Clinical Research Center, University of Iowa Hospitals and Clinics). Detailed information about the reliability and validity of its tools for image analysis have been previously described (28-31). In brief, a three-dimensional data set was created, and the images were then realigned, resampled, and transformed into Talairach and Tournoux atlas space (32). Within the stereotaxic space, boxes were assigned to specific brain regions. Intracranial volume was divided into brain tissue and CSF. Brain tissue was subdivided into the cerebrum and the cerebellum, and cerebrum was further divided into its four lobes. Total CSF volume was broken down into internal CSF (including ventricles and cisterns) and surface CSF. Volumes of tissue were then obtained from each region in an automated fashion. This automated stereotaxic-based method has been reported to be efficient and accurate for cerebral lobe measures (33). To further classify tissue volumes into gray and white matter, we employed another fully automated method of tissue segmentation based on discriminant function analysis that used data from the $\mathrm{T}_{1}$ and proton density/ $\mathrm{T}_{2}$ sequences (34). Intraclass correlations for the automated MRIbased segmented image analysis and brain region volumetric measurements ranged from 0.97 to 0.98 . Total cerebral gray matter volume, total cerebral white matter volume, and gray and white matter volumes of each cerebral lobe were obtained for analysis.

In addition to volumetric brain measures, quantitative indices of surface anatomy were obtained through a method that generated a triangle-based isosurface: cortical thickness (cerebral cortical depth, sulcal cortical depth, gyral cortical depth), sulcal curvature index, gyral curvature index, cortical surface area, and surface complexity index (35).

\section{Statistical Analysis}

Because of the skewed distribution in duration of untreated initial psychosis, analyses were performed by using nonparametric statistics. Spearman's rank order correlation coefficients were 
TABLE 1. Relation of Duration of Untreated Psychosis to Cognitive Deficits in Patients With First-Episode Schizophrenia

\begin{tabular}{|c|c|c|c|c|c|c|}
\hline \multirow{2}{*}{$\begin{array}{l}\text { Domain of Neurocognitive } \\
\text { Functioning }\end{array}$} & \multicolumn{2}{|c|}{$\begin{array}{l}\text { Averaged z Score for Tests } \\
\text { With Domain }\end{array}$} & \multicolumn{2}{|c|}{$\begin{array}{c}\text { Spearman's Correlation } \\
\text { With Duration of Untreated } \\
\text { Psychosis }(\mathrm{N}=156)\end{array}$} & \multicolumn{2}{|c|}{$\begin{array}{c}\text { Wilcoxon's Rank Sum Test of Difference } \\
\text { Between Groups Divided } \\
\text { at Median Duration of Untreated } \\
\text { Psychosis (N=149-156) }\end{array}$} \\
\hline & Mean & SD & $r_{\mathrm{S}}$ & $p$ & $\mathrm{Z}$ & $p$ \\
\hline Verbal memory & -1.35 & 0.98 & -0.14 & 0.08 & -1.9 & 0.05 \\
\hline Nonverbal memory & -0.85 & 1.13 & -0.03 & 0.76 & 0.12 & 0.90 \\
\hline Working memory & -1.17 & 0.99 & -0.11 & 0.18 & -1.5 & 0.15 \\
\hline Language & -1.41 & 1.60 & -0.02 & 0.78 & -0.8 & 0.43 \\
\hline Visuospatial skills & -1.09 & 1.37 & -0.12 & 0.13 & -1.1 & 0.25 \\
\hline Problem solving & -1.39 & 1.11 & -0.15 & 0.07 & -1.6 & 0.12 \\
\hline Initiation/speed & -0.91 & 0.87 & -0.06 & 0.44 & -0.5 & 0.61 \\
\hline Sustained/selective attention & -1.21 & 1.37 & -0.11 & 0.16 & -1.5 & 0.13 \\
\hline Motor skills & -0.65 & 0.98 & -0.13 & 0.12 & -0.7 & 0.47 \\
\hline
\end{tabular}

used to examine the relationships between duration of untreated initial psychosis and the nine neurocognitive domains. Spearman's partial correlation coefficients were used to examine the relationships between duration of untreated initial psychosis and the MRI-based brain morphology measurements. Height and age were used as covariates. Height was used to account for differences in brain measurements across gender. Older age was associated with longer duration of untreated initial psychosis $(\mathrm{r}=0.35$, $\mathrm{N}=156, \mathrm{p}<0.0001$ ), and older age also correlated with smaller brain tissue volumes $(\mathrm{r} \leq 0.44, \mathrm{~N}=102$, all $\mathrm{p}<0.0001)$.

Patients were also divided into two groups on the basis of the median duration of untreated initial psychosis to further examine the effects of untreated psychosis. Wilcoxon's rank sum test was used to compare differences in neurocognitive functioning between groups with short and long duration of untreated initial psychosis. Analysis of covariance (ANCOVA) methods were used to examine the effects of grouping by short versus long duration of untreated initial psychosis on MRI-based brain morphology measures. The covariates in these general linear statistical models were age, height, and gender. The results were considered to be statistically significant at or below the $5 \%$ probability level. All statistical tests were two-tailed.

\section{Results}

The mean duration of untreated initial psychosis for the study group was 74.3 weeks $(\mathrm{SD}=145.1$, median $=13.0,25$ th and 75 th interquartile range $=52$ ). In this group, female subjects had a longer duration of untreated initial psychosis (median $=15.0$ weeks, interquartile range $=69$ ) than male subjects (median $=13.0$ weeks, interquartile range $=$ 43) (Wilcoxon's rank sum $\mathrm{z}=0.94, \mathrm{~N}=156, \mathrm{p}=0.35$ ).

Of the 156 subjects, 102 had MRI brain volumetric data available for analysis. Thirteen subjects did not have scans at intake. Thirty subjects had scans that were obtained by using noncomparable imaging parameters: 21 on an older scanning protocol and nine on a newer protocol. Eleven subjects had poor quality scans. These 54 subjects were no different from the 102 subjects who had available MRI brain volumetric data with regard to gender composition $(64.8 \%$ men [ $\mathrm{N}=35]$ versus $60.8 \%$ men $[\mathrm{N}=62]$, respectively) $\left(\chi^{2}=\right.$ $0.24, \mathrm{df}=1, \mathrm{p}=0.62$ ), age at onset (mean $=22.3$ years, $\mathrm{SD}=6.7$, versus mean $=22.9$ years, $\mathrm{SD}=6.8)(\mathrm{t}=0.50, \mathrm{df}=154, \mathrm{p}=0.62)$, age at first hospitalization (mean $=25.0$ years, $\mathrm{SD}=8.5$, versus mean=26.2 years, $\mathrm{SD}=8.9)(\mathrm{t}=0.83, \mathrm{df}=154, \mathrm{p}=0.44)$, duration of untreated initial psychosis (median=16.5 weeks, inter- quartile range $=100$, versus median $=13.0$, interquartile range $=44$ ) (Wilcoxon's rank sum $\mathrm{z}=1.34, \mathrm{~N}=156, \mathrm{p}=0.18$ ), or illness severity (negative symptom severity: mean $=12.2$, $\mathrm{SD}=3.1$, versus mean $=11.2, \mathrm{SD}=3.8)(\mathrm{t}=1.63, \mathrm{df}=154, \mathrm{p}=0.11)$ (positive symptom severity: mean $=12.6, \mathrm{SD}=3.5$, versus mean=11.6, $\mathrm{SD}=3.8)(\mathrm{t}=1.66, \mathrm{df}=154, \mathrm{p}=0.10)$.

The relation of the duration of untreated initial psychosis with the nine cognitive domains, the MRI-based brain volumetric measures, and the surface anatomy indices are summarized in Table 1 and Table 2. The mean cognitive domain scores for the 156 subjects ranged from -0.65 to 1.41 (Table 1), indicating that there were generalized cognitive deficits involving all nine domains of functioning. The severity of impairment was between 0.5 and 1.5 standard deviations below the mean (of zero). The Spearman's correlation coefficient values between duration of untreated initial psychosis and the cognitive domains were small (all $|\mathrm{r}| \leq 0.15, \mathrm{~N}=156$, all $\mathrm{p} \geq 0.07$ ). Although longer duration of untreated initial psychosis was related to poorer verbal memory $(\mathrm{r}=-0.14, \mathrm{~N}=156, \mathrm{p}=0.08)$ and to poorer problem-solving skills $(\mathrm{r}=-0.15, \mathrm{~N}=156, \mathrm{p}=0.07)$, these correlations did not achieve statistical significance.

Spearman's partial correlation values between duration of untreated initial psychosis and brain volumetric measures and with surface anatomy indices, with control for height and age, were no greater than 0.16 (Table 2). The strongest association was seen in the lateral ventricle volume, with larger ventricles related to longer duration of untreated initial psychosis. However, none of the relationships between duration of untreated initial psychosis and brain volumetric and surface measurements reached statistical significance (all $\mathrm{p} \geq 0.12$ ).

In general, there was paucity of statistically significant differences between groups with short or long duration of untreated initial psychosis with regard to cognitive deficits and brain measures (Table 1 and Table 2). The only cognitive domain that differed significantly between the two groups was verbal memory (Table 1). Patients with a short duration of untreated initial psychosis had less impairment in verbal memory than those with a long duration of untreated initial psychosis (mean $=-1.21, \mathrm{SD}=0.97$, versus mean $=-1.51, \mathrm{SD}=$ 0.98 , respectively) (Wilcoxon's rank sum $\mathrm{z}=1.9, \mathrm{~N}=156, \mathrm{p}=$ 
TABLE 2. Relation of Duration of Untreated Psychosis to Brain Morphology in 156 Patients With First-Episode Schizophrenia

\begin{tabular}{|c|c|c|c|c|c|c|}
\hline \multirow[b]{2}{*}{ Brain Morphology Variable } & \multirow[t]{2}{*}{ Mean } & \multirow[t]{2}{*}{ SD } & \multicolumn{2}{|c|}{$\begin{array}{c}\text { Partial Spearman's Correlation } \\
\text { With Duration of Untreated } \\
\text { Psychosis }^{\mathrm{a}}\end{array}$} & \multicolumn{2}{|c|}{$\begin{array}{l}\text { Analysis of Covariance for } \\
\text { Difference Between Groups } \\
\text { Divided at Median Duration } \\
\text { of Untreated Psychosis }\end{array}$} \\
\hline & & & $r_{s}$ & $\mathrm{p}$ & $\mathrm{F}$ & $\mathrm{p}$ \\
\hline \multicolumn{7}{|l|}{ Volumetric measures $(\mathrm{cc})^{\mathrm{c}}$} \\
\hline Cerebral tissue & 1,147 & 137 & 0.07 & 0.48 & 0.16 & 0.69 \\
\hline Cerebellar tissue & 136.7 & 19.3 & 0.05 & 0.63 & 0.27 & 0.61 \\
\hline Lateral ventricles & 15.2 & 6.7 & 0.16 & 0.12 & 1.45 & 0.23 \\
\hline Surface CSF & 63.7 & 35.9 & 0.06 & 0.55 & 0.05 & 0.82 \\
\hline \multicolumn{7}{|l|}{ Gray matter } \\
\hline Total cerebral & 687.2 & 86.3 & 0.07 & 0.49 & 0.19 & 0.66 \\
\hline Frontal lobe & 267.2 & 38.2 & 0.07 & 0.47 & 0.57 & 0.45 \\
\hline Temporal lobe & 152.9 & 17.8 & 0.06 & 0.53 & 0.02 & 0.90 \\
\hline Parietal lobe & 138.1 & 19.5 & 0.06 & 0.55 & 0.02 & 0.89 \\
\hline Occipital lobe & 68.0 & 12.0 & 0.04 & 0.69 & 0.10 & 0.75 \\
\hline \multicolumn{7}{|l|}{ White matter } \\
\hline Total cerebral & 459.9 & 63.3 & 0.07 & 0.47 & 1.86 & 0.18 \\
\hline Frontal lobe & 177.1 & 24.8 & 0.07 & 0.47 & 0.90 & 0.34 \\
\hline Temporal lobe & 71.6 & 10.3 & 0.12 & 0.22 & 2.93 & 0.09 \\
\hline Parietal lobe & 113.4 & 17.0 & 0.07 & 0.49 & 2.59 & 0.11 \\
\hline Occipital lobe & 53.7 & 11.9 & 0.05 & 0.59 & 0.87 & 0.35 \\
\hline \multicolumn{7}{|l|}{ Surface anatomy measures ${ }^{d}$} \\
\hline Cerebral cortical depth (mm) & 2.1 & 0.3 & -0.05 & 0.61 & 2.38 & 0.13 \\
\hline Sulcal cortical depth (mm) & 1.8 & 0.2 & -0.08 & 0.45 & 3.91 & 0.05 \\
\hline Gyral cortical depth (mm) & 2.3 & 0.4 & -0.04 & 0.69 & 1.71 & 0.19 \\
\hline Sulcal curvature index & -310.4 & 4.1 & -0.04 & 0.72 & 0.02 & 0.90 \\
\hline Gyral curvature index & 290.9 & 4.3 & 0.07 & 0.49 & 0.49 & 0.48 \\
\hline Cerebral surface area $\left(\mathrm{mm}^{3}\right)$ & 177,596 & 19,318 & 0.10 & 0.38 & 0.30 & 0.58 \\
\hline Surface complexity index & 1,626 & 71 & 0.10 & 0.33 & 0.05 & 0.83 \\
\hline
\end{tabular}

a Covariates were age and height.

${ }^{b}$ Covariates were age, height, and gender. For volumetric measures, $d f=1,101$; for surface anatomy measures, $d f=1,89$.

${ }^{c} \mathrm{~N}=102$.

${ }^{\mathrm{d}} \mathrm{N}=90$.

0.05). The two groups did not differ significantly in brain volumetric measures. No differences in surface anatomy indices were observed between the groups with short and long duration of untreated initial psychosis except for sulcal cortical depth $(\mathrm{F}=3.91, \mathrm{df}=1,89, \mathrm{p}=0.05)$. Patients with a short duration of untreated initial psychosis had significantly thicker sulcal cortical depth (mean $=1.90 \mathrm{~mm}, \mathrm{SD}=0.23$, versus mean $=1.77 \mathrm{~mm}, \mathrm{SD}=0.17$, respectively).

\section{Discussion}

In this study, we examined the relationship between duration of untreated initial psychosis and neurocognitive functioning and brain morphology, as assessed when patients with schizophrenia first presented for treatment. We found no evidence of an association between duration of untreated initial psychosis and cognitive deficits, brain volumetric measures, or brain surface anatomical indices. None of the correlation coefficients achieved statistical significance. When the study group was divided on the basis of the median duration of untreated initial psychosis, there were again no significant differences between the groups with long and short duration of untreated initial psychosis except on two measures (verbal memory and cortical sulcal depth). In general, our data do not provide compelling evidence that long periods of untreated psy- chosis are associated with greater deficits in neurocognitive functioning or in brain morphology.

To our knowledge, this is by far the largest study to examine the neurocognitive and brain morphology correlates of duration of untreated initial psychosis. Our study had the power to detect at least small to moderate correlations. It provided $80 \%$ power (alpha $=0.05$ ) to detect a correlation of 0.22 or greater. We employed state-of-the-art MRI technology and image analysis to improve the sensitivity for detecting subtle differences in brain volume and surface anatomy.

Our findings are consistent with two previous studies that examined the relation between duration of untreated initial psychosis and structural brain morphology. Hoff et al. (19) reported that Spearman's rank order correlations between duration of untreated initial psychosis and measures of the lateral ventricles, cerebral hemisphere, and temporal lobe ranged from 0.03 to 0.15 . None of these correlations was statistically significant in their sample of 50 first-episode schizophrenia patients. Fannon et al. (20) also found no relation between duration of untreated initial psychosis and measures of the whole brain, cortical gray matter, lateral ventricles, third ventricle, temporal lobe, and temporal lobe gray matter.

Previous studies have also failed to find significant associations between duration of untreated initial psychosis and neurocognitive functioning at the time of first presen- 
tation for treatment. In the West London first-episode study of schizophrenia, Barnes et al. (22) reported that neurocognitive performance of patients with more than 26 weeks of untreated initial psychosis did not differ significantly from that of patients with shorter duration of untreated initial psychosis. Only performance on one neurocognitive measure (an attentional set-shifting task) was somewhat worse in the group with a longer duration of untreated initial psychosis. In addition to brain volumetric measures, Hoff et al. (19) also examined the correlations between duration of untreated initial psychosis and seven summary scores from a neurocognitive battery. None of the correlations was significant, and all were within $95 \%$ confidence intervals. In another study of 120 first-episode patients, from the Prevention and Early Intervention Program for Psychosis in London, Ontario, Norman et al. (36) reported that duration of untreated initial psychosis was not related to performance on an extensive battery of cognitive measures.

Structural brain abnormalities and cognitive deficits in schizophrenia are evident by the time patients first come in for treatment (see reviews in references 37,38 ). The neurodevelopmental theory of schizophrenia posits that abnormal genetic and/or epigenetic factors interfere with early brain development (neurulation, cellular proliferation, migration, differentiation, and synaptogenesis) $(39,40)$. Later brain development processes (e.g., apoptosis and synaptic pruning) and/or other neuropathological events (e.g., stress, illicit drug use, head trauma) interact with the already aberrant neuropathology to result in symptoms and signs of schizophrenia. Thus, the structural brain abnormalities and cognitive deficits found in schizophrenia patients may be primarily neurodevelopmental in origin. However, several studies have shown that schizophrenia patients with poor outcome exhibit greater ventricular enlargement over time (41-43, unpublished study by Ho et al.), suggesting that additional pathogenic processes may contribute to further deteriorative progression in these deficits. If such pathogenic processes are also present around the onset of clinical symptoms, it appears that untreated psychosis is not a contributing factor. On the basis of our findings as well as those of other investigators $(19,20,22,36)$, the pattern of mostly small correlation coefficients and the paucity of significant differences between patients with long and short duration of untreated initial psychosis do not support the frequently expressed belief that long periods of untreated psychosis have a pronounced impact on neurocognitive functioning or on brain morphology in schizophrenia.

Among the nine cognitive domains and 21 structural brain measures examined in this study, only two measures were significantly different between the groups with long and short duration of untreated initial psychosis. Patients in the group with long duration of untreated initial psychosis group had significantly greater verbal memory impairment and thinner cortical sulcal depth. These two associations lend support for the "toxic psychosis" hy- pothesis. Although the hypothesis is speculative, glutamate excitotoxicity or glucocorticoid-mediated neuronal damage may result in atrophy in cortical sulcal thickness in patients with long duration of untreated initial psychosis. Long exposure to these purported deleterious effects of untreated psychosis may also lead to greater verbal memory deficits as well. However, there are other possible interpretations for these two significant associations (4, 44). Patients with more severe illness, as evidenced by poorer verbal memory and thinner cortical sulcal depth, may be less able to seek treatment early. Alternatively, we did not correct for multiple testing and kept the $p$ value at the 0.05 level. These two statistically significant associations could also have been type I errors.

Why is there conflicting evidence over the association between duration of untreated initial psychosis and outcome? Some studies have found long duration of untreated initial psychosis to be associated with poorer outcome (7-16), while others have not (17-22). The reasons for these conflicting findings may be related to differences in sampling, power, and statistical methods $(4,45)$ as well as in the reliability and validity of measuring the duration of untreated initial psychosis (46). Since the distribution in the duration of untreated initial psychosis is often skewed, nonparametric statistics are more appropriate for analysis. The duration of untreated initial psychosis, as it is retrospectively assessed, is subject to recall bias. Most studies do not report measures of reliability in ascertaining the duration of untreated initial psychosis, and only a few studies have used multiple sources of information (i.e., patients, family members, and available medical records) to improve reliability. While all studies assume psychosis to be persistent from onset, this may not apply for all patients, especially those with a long duration of untreated initial psychosis, in which there may have been spontaneous remissions. Hence, defining the duration of untreated initial psychosis as the time interval between the onset of psychosis and treatment may not be valid in a proportion of patients.

Despite conflicting evidence over the association of duration of untreated initial psychosis and outcome, the lengthy delays in seeking treatment have been frequently replicated. Consistent with previous first-episode study groups, we observed long delays between the onset of psychotic symptoms and initiation of treatment in a substantial proportion of our study group. Although one-half of our group sought treatment within 3 months of the onset of psychotic symptoms, one-quarter of the group delayed treatment for up to 76 weeks, and the remaining patients deferred treatment beyond 76 weeks. Such lengthy delays are undesirable, since deferring effective treatments leads to unnecessary and undue suffering for both patients and their families. This reason alone justifies efforts to reduce treatment delays, irrespective of whether early intervention improves outcome or whether untreated psychosis is neurotoxic. Pioneering early identification programs in Australia and Norway have demonstrated that treatment 
delays can be shortened $(13,47)$. These programs have proven that the innovative triad of networking with community providers, carefully targeted educational activities, and dedicated early detection teams can lead to timely referral and earlier treatment of patients with psychotic disorders. Programs like the Early Psychosis Prevention and Intervention Centre, TIPS, RAP (48), PRIME (49), and the Prevention and Early Intervention Program for Psychosis (36) also offer hope that future sufferers of schizophrenia will benefit from early interventive measures.

Presented in part at the Seventh International Congress on Schizophrenia Research, Santa Fe, N.M., April 17-21, 1999, and at the Second International Conference on Early Psychosis, New York, March 31 through April 2, 2000. Received June 11, 2002; revision received Aug. 29, 2002; accepted Sept. 10, 2002. From the Mental Health Clinical Research Center, Department of Psychiatry, University of Iowa College of Medicine and the University of lowa College of Public Health; and the MIND Institute, Department of Psychiatry, University of New Mexico, Albuquerque. Address reprint requests to Dr. Ho, Department of Psychiatry, 2880 JPP, University of lowa College of Medicine, 200 Hawkins Dr., lowa City, IA 52242; beng-ho@uiowa.edu (e-mail).

Supported in part by NIMH grants $\mathrm{MH}-31593, \mathrm{MH}-40856$, and $\mathrm{MH}-$ 43271.

Appendix 1. Nine Cognitive Domains and Component Neuropsychological Tests Administered to Patients With Untreated First-Episode Schizophrenia

1. Verbal memory

Rey Auditory Verbal Learning Test-trials 1-5, trial 7, and delayed recall

WAIS-R Logical Memory-immediate and delayed recall

2. Nonverbal memory

Rey-Osterrieth Complex Figure Test-immediate and delayed recall Benton Visual Retention Test-total number correct

3. Working memory

WAIS-R arithmetic subtest

WAIS-R digit span subtest

4. Language skills

WAIS-R vocabulary subtest

Shipley Institute of Living Scale-vocabulary

5. Visuospatial skills

Rey-Osterrieth Complex Figure Test-copy

WAIS-R block design subtest

WAIS-R object assembly subtest

Judgment of Line Orientation

6. Initiation and speed

Multilingual Aphasia Examination controlled oral word

association subtest

WAIS-R digit symbol subtest

Trail Making Test A

Stroop-trials 1 and 2

Alpha Tree Test

Alpha Curved Test

7. Sustained and selective attention

Stroop-trial 3

Trail Making Test B

Continuous Performance Test-proportion of hits

Circle A Letter-Cancellation Task

8. Problem solving

Wisconsin Card Sorting Test-categories and perseverative errors Shipley Institute of Living Scale-abstractions

WAIS-R comprehension subtest

WAIS-R similarities subtest

WAIS-R picture completion subtest

WAIS-R picture arrangement

9. Motor skills

Finger Tapping-left- and right-hand averages Purdue Pegboard-left, right, and both hands

\section{References}

1. McGlashan TH: Duration of untreated psychosis in first-episode schizophrenia: marker or determinant of course? Biol Psychiatry 1999; 46:899-907

2. McGorry PD: Evaluating the importance of reducing the duration of untreated psychosis. Aust NZ J Psychiatry 2000; 34(suppl): S145-S149

3. Lieberman JA, Fenton WS: Delayed detection of psychosis: causes, consequences, and effect on public health (editorial). Am J Psychiatry 2000; 157:1727-1730

4. Ho B-C, Andreasen NC: Long delays in seeking treatment for schizophrenia. Lancet 2001; 357:898-900

5. Wyatt RJ: Neuroleptics and the natural course of schizophrenia. Schizophr Bull 1991; 17:325-351

6. Wyatt RJ: Early intervention for schizophrenia: can the course of the illness be altered? Biol Psychiatry 1995; 38:1-3

7. Johnstone EC, Crow TJ, Johnson AL, MacMillan JF: The Northwick Park Study of first episodes of schizophrenia, I: presentation of the illness and problems relating to admission. Br J Psychiatry 1986; 148:115-120

8. Loebel AD, Lieberman JA, Alvir JM, Mayerhoff DI, Geisler SH, Szymanski SR: Duration of psychosis and outcome in first-episode schizophrenia. Am J Psychiatry 1992; 149:1183-1188

9. Waddington JL, Youssef HA, Kinsella A: Sequential cross-sectional and 10-year prospective study of severe negative symptoms in relation to duration of initially untreated psychosis in chronic schizophrenia. Psychol Med 1995; 25:849-857

10. McGorry PD, Edwards J, Mihalopoulos C, Harrigan SM, Jackson HJ: EPPIC: an evolving system of early detection and optimal management. Schizophr Bull 1996; 22:305-326

11. Wyatt RJ, Green MF, Tuma AH: Long-term morbidity associated with delayed treatment of first admission schizophrenic patients: a re-analysis of the Camarillo State Hospital data. Psychol Med 1997; 27:261-268

12. Haas GL, Garratt LS, Sweeney JA: Delay to first antipsychotic medication in schizophrenia: impact on symptomatology and clinical course of illness. J Psychiatr Res 1998; 32:151-159

13. Carbone S, Harrigan S, McGorry PD, Curry C, Elkins K: Duration of untreated psychosis and 12-month outcome in first-episode psychosis: the impact of treatment approach. Acta Psychiatr Scand 1999; 100:96-104

14. Larsen TK, Moe LC, Vibe-Hansen L, Johannessen JO: Premorbid functioning versus duration of untreated psychosis in 1 year outcome in first-episode psychosis. Schizophr Res 2000; 45:1-9

15. Drake RJ, Haley CJ, Akhtar S, Lewis SW: Causes and consequences of duration of untreated psychosis in schizophrenia. Br J Psychiatry 2000; 177:511-515

16. Black K, Peters L, Rui Q, Milliken H, Whitehorn D, Kopala LC: Duration of untreated psychosis predicts treatment outcome in an early psychosis program. Schizophr Res 2001; 47:215222

17. Craig TJ, Bromet EJ, Fennig S, Tanenberg-Karant M, Lavelle J, Galambos N: Is there an association between duration of untreated psychosis and 24-month clinical outcome in a first-admission series? Am J Psychiatry 2000; 157:60-66

18. Ho B-C, Andreasen NC, Flaum M, Nopoulos P, Miller D: Untreated initial psychosis: its relation to quality of life and symptom remission in first-episode schizophrenia. Am J Psychiatry 2000; 157:808-815; correction, 2001; 158:986

19. Hoff AL, Sakuma M, Razi K, Heydebrand G, Csernansky JG, DeLisi LE: Lack of association between duration of untreated illness and severity of cognitive and structural brain deficits at the first episode of schizophrenia. Am J Psychiatry 2000; 157 : 1824-1828

20. Fannon D, Chitnis X, Doku V, Tennakoon L, Ó'Ceallaigh S, Soni W, Sumich A, Lowe J, Santamaria M, Sharma T: Features of 
structural brain abnormality detected in first-episode psychosis. Am J Psychiatry 2000; 157:1829-1834

21. de Haan L, van Der Gaag M, Wolthaus J: Duration of untreated psychosis and the long-term course of schizophrenia. Eur Psychiatry 2000; 15:264-267

22. Barnes TR, Hutton SB, Chapman MJ, Mutsatsa S, Puri BK, Joyce EM: West London first-episode study of schizophrenia: clinical correlates of duration of untreated psychosis. Br J Psychiatry 2000; 177:207-211

23. Olney JW, Farber NB: Glutamate receptor dysfunction and schizophrenia. Arch Gen Psychiatry 1995; 52:998-1007

24. McEwen BS: Effects of adverse experiences for brain structure and function. Biol Psychiatry 2000; 48:721-731

25. Andreasen NC, Flaum M, Arndt S: The Comprehensive Assessment of Symptoms and History (CASH): an instrument for assessing diagnosis and psychopathology. Arch Gen Psychiatry 1992; 49:615-623

26. Andreasen NC: Scale for the Assessment of Negative Symptoms (SANS). Iowa City, University of lowa, 1983

27. Andreasen NC: Scale for the Assessment of Positive Symptoms (SAPS). lowa City, University of lowa, 1984

28. Andreasen NC, Cohen G, Harris G, Cizadlo T, Parkkinen J, Rezai K, Swayze VW II: Image processing for the study of brain structure and function: problems and programs. J Neuropsychiatry Clin Neurosci 1992; 4:125-133

29. Andreasen NC, Cizadlo T, Harris G, Swayze V II, O'Leary DS, Cohen G, Ehrhardt J, Yuh WT: Voxel processing techniques for the antemortem study of neuroanatomy and neuropathology using magnetic resonance imaging. J Neuropsychiatry Clin Neurosci 1993; 5:121-130

30. Andreasen NC, Harris G, Cizadlo T, Arndt S, O'Leary D, Swayze $\mathrm{V}$, Flaum M: Techniques for measuring sulcal/gyral patterns in the brain as visualized through magnetic resonance scanning: BRAINPLOT and BRAINMAP. Proc Natl Acad Sci USA 1994; 91: 93-97

31. Cohen G, Andreasen NC, Alliger R, Arndt S, Kuan J, Yuh WTC, Ehrhardt J: Segmentation techniques for the classification of brain tissue using magnetic resonance imaging. Psychiatry Res Neuroimaging 1992; 45:33-51

32. Talairach J, Tournoux P: Co-Planar Stereotaxic Atlas of the Human Brain: Three-Dimensional Proportional System. New York, Thieme Medical, 1988

33. Andreasen NC, Rajarethinam R, Cizadlo T, Arndt S, Swayze VW II, Flashman LA, O'Leary DS, Ehrhardt JC, Yuh WTC: Automatic atlas-based volume estimation of human brain regions from MR images. J Comp Assist Tomogr 1996; 20:98-106

34. Harris G, Andreasen NC, Cizadlo T, Bailey JM, Bockholt HJ, Magnotta VA, Arndt S: Improving tissue classification in MRI: a three-dimensional multispectral discriminant analysis method with automated training class selection. J Comput Assist Tomogr 1999; 23:144-154
35. Magnotta VA, Andreasen NC, Schultz SK, Harris G, Cizadlo T, Heckel D, Nopoulos P, Flaum M: Quantitative in vivo measurement of gyrification in the human brain: changes associated with aging. Cereb Cortex 1999; 9:151-160

36. Norman RM, Townsend L, Malla AK: Duration of untreated psychosis and cognitive functioning in first-episode patients. $\mathrm{Br} J$ Psychiatry 2001; 179:340-345

37. Shenton ME, Wible CG, McCarley RW: A review of magnetic resonance imaging studies of brain anomalies in schizophrenia, in Brain Imaging in Clinical Psychiatry. Edited by Krishnan KRR, Doraiswamy PM. New York, Marcel Dekker, 1997, pp 297-380

38. Rund BR: A review of longitudinal studies of cognitive functions in schizophrenia patients. Schizophr Bull 1998; 24:425435

39. Murray RM, Lewis SW: Is schizophrenia a neurodevelopmental disorder? Br Med J Clin Res Ed 1987; 295:681-682

40. Weinberger DR: Implications of normal brain development for the pathogenesis of schizophrenia. Arch Gen Psychiatry 1987; 44:660-669

41. Woods BT, Yurgelun-Todd D, Benes FM, Frankenburg FR, Pope HG Jr, McSparren J: Progressive ventricular enlargement in schizophrenia: comparison to bipolar affective disorder and correlation with clinical course. Biol Psychiatry 1990; 27:341352

42. Davis KL, Buchsbaum MS, Shihabuddin L, Spiegel-Cohen J, Metzger M, Frecska E, Keefe RS, Powchik P: Ventricular enlargement in poor-outcome schizophrenia. Biol Psychiatry 1998; 43:783-793

43. Lieberman J, Chakos M, Wu H, Alvir J, Hoffman E, Robinson D, Bilder R: Longitudinal study of brain morphology in first-episode schizophrenia. Biol Psychiatry 2001; 49:487-499

44. Ho B-C, Andreasen NC, Arndt S: The effects of untreated psychosis on symptom severity, cognition, and brain volumes at the time of first hospitalization (abstract). Schizophr Res 1999; 36:20

45. McGorry PD, Harrigan SM, Amminger P, Norman R, Malla A: Untreated initial psychosis (letter). Am J Psychiatry 2001; 158: 1161-1163

46. Ho B-C, Andreasen NC: Duration of initial untreated psychosis-methods and meanings, in Second International Conference on Early Psychosis. Parkville, Victoria, Australia, Early Psychosis Prevention and Intervention Centre, 2000, p 31

47. Larsen TK, McGlashan TH, Johannessen JO, Friis S, Guldberg C, Haahr U, Horneland M, Melle I, Moe LC, Opjordsmoen S, Simonsen E, Vaglum P: Shortened duration of untreated first episode of psychosis: changes in patient characteristics at treatment. Am J Psychiatry 2001; 158:1917-1919

48. Cornblatt B, Obuchowski M, Schnur D, O'Brien JD: Hillside study of risk and early detection in schizophrenia. Br J Psychiatry Suppl 1998; 172:26-32

49. Miller TJ, McGlashan TH: Early identification and intervention in psychotic illness. Conn Med 2000; 64:339-341 